Didáctica Geográfica n 20, 2019, pp. 123-152

ISSN: 0210-492-X

D.L: M-3736-2014

\title{
EL DESARROLLO DE LAS COMPETENCIAS SOCIALES Y CÍVICAS EN CIENCIAS SOCIALES: ITINERARIO DIDÁCTICO POR LOS RESTOS FENICIOS DE ALMUÑE- CAR (GRANADA)
}

Ulises Najarro Martín ${ }^{1}$; Juan Carlos Maroto Martos²

Recibido: 15/05/2019

Aceptado 15/09/2018

\section{RESUMEN:}

En el presente trabajo se propone un itinerario didáctico por los restos fenicios de la localidad de Almuñécar (Granada) dirigido a estudiantes de $1^{\circ}$ de Educación Secundaria Obligatoria (ESO). A través del mismo ponemos especial interés en el desarrollo de las competencias sociales y cívicas (CSC). El legado histórico y patrimonial de Almuñécar es más que evidente, sin embargo, se constata la existencia de recursos/bienes que son insuficientemente conocidos y aprovechados desde un punto de vista didáctico. Se diseña, mediante el uso de un SIG, una cartografía con los principales Puntos de Interés Didáctico con presencia de restos arqueológicos. Además, se pretende trabajar una serie de actividades mediante un cuaderno de campo que permitan conocer el pasado fenicio de la ciudad, la importancia histórica de las colonizaciones fenicias, fomentar valores de sensibilización y de conservación, y elaborar un producto final para solicitar a las autoridades responsables actuaciones encaminadas a poner en valor el patrimonio histórico local.

1 Departamento de Ciencias Sociales. Centro de Enseñanza Secundaria JUAN XXIII Cartuja (Granada). Tel: (34) 6767727 13. Dirección postal (18690): A.V. Juan Carlos I, nº5, $2^{\circ}$ M. Email: ulisesnajarrom@gmail.com

2 Departamento de Geografía Humana. Universidad de Granada. Email: jcmaroto@ugr.es 


\section{Palabras clave:}

Itinerario didáctico, competencias sociales y cívicas, Almuñécar, fenicios.

\section{Abstract:}

In the present work a didactic itinerary is proposed for the Phoenician remains of the town of Almuñécar (Granada) oriented to students of the first year of secondary school. Through it we put special interest in the development of social and civic skills. The historical and patrimonial legacy of Almuñécar is more than evident. However, the existence of assets is verified that are insufficiently known and exploited from a didactic point of view. It is designed through the use of a GIS, a cartography with the main Points of Didactic Interest with the presence of archaeological remains. Furthermore, it is intended to work a series of activities through a field notebook that allows you to know the Phoenician past of your city, the historical importance of the Phoenician colonization, promote awareness and conservation values, and develop a final product to request from the responsible authorities actions aimed at valuing local historical heritage.

\section{KEYWORDS:}

Educational itinerary, social and civic competences, Almuñécar, Phoenicians.

\section{RÉSUMÉ:}

Dans le présent document il se propose un itinéraire didactique pour les rest phéniciens de la ville d'Almuñécar (Granade) destiné aux étudiants de $1^{\circ}$ Enseignement Secondaire Obligatoire. À travers elle, nous accordons un intérêt particulier au développement des compétences sociales et civiques.Le patrimoine historique et patrimonial d'Almuñécar est plus qu'évident, toutefois, on se on constate l'existence de ressources/biens patrimoniaux qui sont insuffisamment connus et explotés depuis une perspective didactique. Il est conque á travers l'usage d'un SIG une cartographie des principaux points d'intérêt didactique et de la présence de vestiges archéologiques. En outre, il est prévu de créer une série d'activités par le biais d'un cahier de terrain vous permettant de connaître le passé phénicien de votre ville, l'importance historique de la colonisation phénicienne, de promouvoir les valeurs de sensibilisation et de conservation et de développer un produit final pour solliciter á l'autorités responsables mesures destinées á mettre en valeur le patrimoine historique local.

\section{Mots-Clés:}

Itinéraire didactique, compétences sociales et civiques, Almuñécar, phéniciens. 


\section{INTRODUCCIÓN}

Los principios en que se inspiran los fines del sistema educativo español están recogidos en la Constitución Española. Entre otros pueden destacarse la pretensión de conseguir la máxima calidad educativa, la equidad para tratar de garantizar la igualdad de derechos y oportunidades entre las personas independientemente de su sexo, edad, religión, etc. y de esta manera tratar de evitar situaciones de discriminación derivadas de circunstancias externas a ellas o producidas por cualquier tipo de discapacidad.

Lo anterior, siguiendo las leyes educativas vigentes, debe realizarse con flexibilidad para tratar de adaptarse a los cambios sociales y al diverso alumnado existente. En última instancia hay que ofrecerles una educación integral, tanto en conocimientos como en valores, que favorezcan la defensa de la libertad individual y colectiva, el ejercicio de la responsabilidad cívica, la extensión de la solidaridad, de la tolerancia/ respeto y la justicia.

En este contexto, la etapa educativa denominada Educación Secundaria Obligatoria (ESO), que tiene un carácter obligatorio y gratuito a lo largo de los cuatro años siguientes a la Educación Primaria (alumnado comprendido entre los 12 y 16 años), tiene como principios generales procurar que los discentes adquirieran conocimientos básicos en los estudios humanísticos, científicos y tecnológicos. También que desarrollen hábitos de trabajo/estudio, así como que ejerciten sus derechos y obligaciones ciudadanas, cuestiones claves para que una vez finalizados estos estudios se incorporen al mundo laboral o continúen la formación postobligatoria de bachillerato (Real Decreto 1105/2014, de 26 de diciembre. Art.10).

El Real Decreto citado, que establece el currículo básico de la Educación Secundaria Obligatoria y del Bachillerato, basa el proceso de enseñanza-aprendizaje, además de en los objetivos, los contenidos, la metodología didáctica, los estándares y resultados de aprendizaje y los criterios de evaluación, en la potenciación de siete competencias transversales que denomina clave y que conceptualiza como un "saber hacer", es decir, que propician el conocimiento a través de la participación activa en prácticas sociales.

Siguiendo las directrices europeas (Recomendación 2006/962/CE del Parlamento Europeo y del Consejo, de 18 de diciembre de 2006), se consideran esenciales para el bienestar de las sociedades europeas, el crecimiento económico y la innovación; llegando a afirmar de ellas que constituyen una combinación de habilidades prácticas, conocimientos, motivación, valores éticos, actitudes, emociones y otros componentes sociales y de comportamiento que se movilizan conjuntamente.

La Orden ECD/65/2015 establece un total de siete competencias clave que son: "comunicación lingüística" (CCL), "competencia matemática y competencias básicas en ciencia y tecnología" (CMCT), "competencia digital" (CD), "aprender a aprender" 
(CAA), "competencias sociales y cívicas" (CSC), "sentido de iniciativa y espíritu emprendedor" (SIEP) y finalmente "conciencia y expresiones cultuales" (CEC), que sin excluir completamente al resto, nos centramos en las "sociales y cívicas (CSC)".

El desarrollo de las competencias sociales y cívicas debe facilitar al alumnado la adquisición de habilidades que favorezcan la utilización de los conocimientos estudiados sobre las dinámicas de las sociedades (tanto pasadas como presentes y a distintas escalas espaciales), para comprender y valorar críticamente la información relevante de sus aportaciones.

\subsection{Metodología}

Como antecedentes en el trabajo de campo, que fue introducido en nuestro país con fines pedagógicos a finales del siglo XIX, es bien conocido que, desde la Institución Libre de Enseñanza, la excursión era parte fundamental de los enfoques pedagógicos tendentes a lograr una educación completa e integradora. Su utilización ha sido creciente y la aplicación de excursiones y salidas de campo se ha convertido en una constante en la educación en España. Insa (2002) define itinerario como un recorrido o camino a seguir con diferentes puntos de parada o de interés en determinados elementos de valor patrimonial o cultural.

Se comparte con Crespo (2012), que especialmente a través del análisis vivencial podemos comprender de manera significativa el papel que desempeñan algunas partes en el conjunto, es decir, identificar las relaciones entre elementos que configuran la realidad que contemplamos. Tal como ya aportó Gómez Ortiz (1986) algunas de las ventajas que ofrecen los itinerarios son: integrar el conocimiento del entorno en el currículo escolar, convierte al alumno en el centro de la práctica y aprendizaje, facilita la visión multidisciplinar del paisaje, consolida el trabajo en equipo del profesorado, fomenta en los alumnos la observación directa de los objetos de estudio, colabora en la creación de un espíritu crítico y permite captar la realidad de manera integrada.

De manera más específica, se ha resaltado el indiscutible potencial didáctico de los itinerarios y excursiones en la enseñanza de las Ciencias Sociales en general y de la Geografía en particular (Gómez, 1986; García, 1994), coincidiendo en que la visita al territorio ofrece al alumnado una posibilidad de comprensión y relación de los hechos geográficos difícilmente alcanzable por medio de otros recursos, facilitando el aprendizaje significativo a través de la experiencia de campo. García $(1993,1994)$ concreta la riqueza de los aprendizajes que se producen en estas actividades fuera del aula: abundancia de motivación, aproximación a lo real, desarrollo de vocabulario preciso, aprendizaje de la observación, capacidad de analizar, comprender, practicar destrezas, capacidad crítica y desarrollo de valores éticos. 
Pero hay que tener en cuenta, como acertadamente indican Pontuschka y Cacete (2007), que las salidas de campo en la enseñanza de la Geografía son una metodología interdisciplinar, puesto que el espacio que se estudia es dinámico y está en continua transformación, por lo que se requiere del conocimiento de diversas disciplinas para poder interpretarlo (historia, economía, sociología, etc.).

En el caso concreto del presente itinerario debemos destacar la importancia de la historia local para las enseñanzas medias y las potencialidades que ofrece tanto al docente como al alumnado, pues como indica Olave (2005), debe utilizarse el espacio geográfico y especialmente la historia del entorno en que vive el/la estudiante, ya que como sugiere Fuente Martínez (2015), el conocimiento del entorno estimula en el alumnado el ansia de conocer y de aplicar el conocimiento adquirido en diferentes contextos a los que tenga que hacer frente.

En definitiva existe un amplio consenso en que los itinerarios didácticos son una herramienta útil para el profesorado de Educación Secundaria Obligatoria (ESO) que quiera innovar en la enseñanza de la Geografía y de la Historia y en sus metodologías docentes. Mínguez (2010), afirma que se trata del método por excelencia para la enseñanza y el aprendizaje de la Geografía y que puede ser utilizado en todos los niveles educativos.

Para tratar los contenidos del tema, si atendemos a las tipologías y según las propuestas de itinerarios didácticos que realizan Liceras y Romero (2016), la propuesta de itinerario se enmarcaría dentro del ámbito histórico cultural, en concreto en lo que respecta a los restos arqueológicos y a los museos.

Se ha considerado que el itinerario, para que logre los efectos educativos esperados, debe ser insertado en la programación didáctica de la materia disciplinar, así como preparado y planificado antes de realizarse. A lo anterior debe seguirle la ejecución del recorrido y finalmente se culminará en el aula con una reflexión que facilite la consecución de los fines diseñados.

Debe advertirse que como marco de referencia legal, además del citado Real Decreto 1105/2014, de 26 de diciembre, se ha utilizado también el Decreto 111/2016, de 14 de junio, que será donde se concrete el currículo para la ESO en la Comunidad Autónoma de Andalucía. En él se recogen los contenidos vinculados con el presente itinerario didáctico dentro del área de Ciencias Sociales: Geografía e Historia. El itinerario se enmarca dentro del "Bloque 2. La Historia": La Historia Antigua; las primeras civilizaciones. Culturas urbanas. Mesopotamia y Egipto. Sociedad, economía y cultura. El Argar. Los cauces de relación de Andalucía con las civilizaciones mediterráneas; colonizaciones fenicias y griegas. 


\subsection{La importancia de los fenicios en la Península Ibérica}

El interés del estudio de los fenicios radica en que se trata de un pueblo poco conocido ya que no lograron disponer de un territorio perfectamente delimitado con una capital política. Ello no les impidió alcanzar una enorme importancia económica en el Mediterráneo e influencia cultural, como consecuencia de su gran capacidad comercial basada en técnicas de transacciones muy eficientes, sustentadas en un excelente control sobre la navegación. Con base en el Mediterráneo Oriental, en lo que hoy son las costas de Líbano, Israel y Siria, lograron no sólo establecer factorías por doquier, sino también relacionarse con ciudades-estado independientes y con otras pertenecientes a otros pueblos, tanto del este del Mediterráneo, como del oeste, norte y sur. Sus factorías compartieron, además de ubicarse en lugares con una orografía que las facilitase la defensa de eventuales enemigos temporales: egipcios, asirios, babilonios, persas, etc., lengua, cultura y religión, circunstancias que propiciaron además del tráfico comercial, el siempre enriquecedor intercambio cultural.

Una didáctica visión de ellos para este nivel educativo lo proporciona, además del libro de texto, diversos materiales audiovisuales existentes. De entre ellos, hemos seleccionado para que sea visualizado en el aula, antes de realizar el itinerario, el titulado: "Los Fenicios, el Mediterráneo y el comercio marítimo", que se localiza en la plataforma YouTube y es de acceso libre.

La costa andaluza fue una zona de interés para fenicios, destacando el caso de Cádiz y también en la costa de Granada el asentamiento de SEK, la hoy Almuñécar, que dispone de numerosos recursos que han sido catalogados como BIC (Bienes de Interés Cultural) y son todo un referente que le otorga identidad a la ciudad en el contexto de Andalucía. Maroto y Najarro (2018), pusieron de manifiesto la importancia de los recursos históricos fenicios de Almuñécar para potenciar el turismo cultural en la localidad e incluso para insertarla en la Ruta Cultural Fenicia del Mediterráneo.

Justifica también la elección de este tema, la enorme importancia que tienen los restos fenicios en la ciudad. Como se ha comentado más arriba, arqueólogos e historiadores consideran a los fenicios, no sólo como los fundadores de Almuñécar, sino también quienes lograron insertar este núcleo en una ruta comercial que puso en contacto a ciudades del diverso y complejo mundo Mediterráneo. Transitaron de este a oeste y de norte y sur sus orillas y propiciaron aquí unos momentos de esplendor, que tuvo consecuencias en su organización social y territorial, como atestiguan los restos que disponemos.

A lo anterior se une la circunstancia de que algunos de estos recursos presentan problemas de protección y acondicionamiento. En la actualidad, el estado de deterioro y abandono es más que evidente, pasando la mayoría desapercibidos por parte de las instituciones responsables, la población local y los centros de enseñanza secundaria. El 
desconocimiento de la historia local es axiomático y justifica la finalidad y utilidad del presente itinerario.

\subsection{Puntos de interés didáctico (PID) y objetivos del trabajo}

Se han elegido seis Puntos de Interés Didáctico (en adelante PID): Monumento al fenicio, Necrópolis de Montevelilla, Museo Arqueológico Cueva Siete Palacios, Factoría de los Salazones Parque del Majuelo, Necrópolis de Laurita y Necrópolis de Puente de Noy.

El principal objetivo es desarrollar fundamentalmente la competencia social y cívica en el alumnado de $1^{\circ}$ de ESO a través de un itinerario didáctico por los restos fenicios existentes en el municipio de Almuñécar.

Esto se concreta en los siguientes objetivos específicos que han sido descritos en base a los criterios de evaluación establecidos en la Orden de 14 de julio de 2016, por la que se desarrolla el currículo correspondiente a la Educación Secundaria Obligatoria en la Comunidad Autónoma de Andalucía:

- Conocer la enorme riqueza histórica, cultural y patrimonial que la civilización fenicia ha legado en numerosos espacios de la localidad.

- Acotar en el espacio y el tiempo los orígenes de la civilización fenicia, sus oleadas de expansión por el mediterráneo y el lugar que ocupó Almuñécar.

- Identificar los rasgos básicos de las formas de asentamiento, de su economía, sus objetos, costumbres y ritos funerarios.

- Interpretar la cartografía del recorrido para desarrollar el sentido espacial.

- Adquirir sensibilidad hacia el patrimonio histórico de su localidad, así como una conciencia sobre la importancia del mismo.

- Fomentar valores de conservación, respeto, y puesta en valor con criterios de sostenibilidad del legado de las sociedades del pasado.

\section{DISEÑO DEL ITINERARIO}

\subsection{Cuestiones tenidas en cuenta para diseñar el itinerario}

Antes de conocer las principales características del itinerario, se hace necesario mostrar algunas de las particularidades de los discentes, la peculiaridad de la asignatura y las dificultades objetivas que existen para favorecer el proceso de enseñanza-aprendizaje de sus contenidos. Lo anterior debe tener presente también, tanto el papel del profesorado como de las familias para propiciar el desarrollo de las competencias sociales y cívicas que se pretenden trabajar. Finalmente, el conocimiento del lugar donde se aplica el itinerario didáctico es fundamental para su correcto desarrollo. 


\section{Ulises Najarro Martín y Juan Carlos Maroto Martos}

El alumnado de ESO se caracteriza por encontrarse en la etapa de la pre-adolescencia, momento de cambios tanto físicos como psicológicos que les conduce a una intensa búsqueda de su identidad. Las alteraciones hormonales que padecen, propicia que tengan dificultades de atención, estados de irritabilidad, e incluso de agresividad, Sobrado, L. (2000). Lo anterior debe tenerse en cuenta por el/la docente para favorecer el proceso de enseñanza-aprendizaje, siendo frecuente que se les recomiende no ridiculizarle, evitar tanto la rigidez como la ausencia total de normas en las clases, fomentar el diálogo continuo y su autoconfianza, valorar sus logros, etc.

Es un momento también muy especial desde el punto de vista intelectual ya que empiezan a adquirir capacidades de pensamiento abstracto que van a propiciar que reflexionen más, que formulen hipótesis, que aumente su capacidad deductiva e incluso que traten de fijar sus opiniones. Sus experiencias personales y las actuaciones de las amistades en las que confían suelen pesar más en sus decisiones, que las recomendaciones de sus familiares. Son nativos digitales. En consecuencia, el uso de materiales audiovisuales, que son importantes para ellos, constituye una buena opción para potenciar el proceso de enseñanza-aprendizaje.

De acuerdo con Liceras (2000), las dificultades que tiene el alumnado para aprender Ciencias Sociales están relacionadas con el abuso que todavía se hace de la memorización no comprensiva, de los cambios que en este nivel se introducen de primar la enseñanza explicativa frente a la meramente descriptiva.

A lo anterior se suma la necesidad de recurrir a integrar conocimientos procedentes de diferentes disciplinas y su carácter dinámico. Esto supone no sólo que el alumnado debe esforzarse para ganar claridad y precisión conceptual, sino que también debe ser capaz de asimilar que la comprensión de los hechos y fenómenos sociales, precisa recurrir a explicaciones poli-causales de diferente complejidad.

Así por ejemplo, nociones geográficas como espacio, medio, territorio, ubicación, localización, emplazamiento, escalas espaciales, coordenadas geográficas o los conceptos históricos como tiempo cronológico, tiempo histórico, u otros como civilizaciones, culturas, sociedades, pueblos, grupos sociales, oligarquías, patrimonio, etc., exigen no sólo su estudio, sino también oportunidades para poder usarlas en actividades que estén relacionadas con su realidad cotidiana, a fin de que se favorezca su aprendizaje significativo.

En este proceso el profesorado es fundamental, ya que debe ser capaz de lograr la transposición didáctica. Las clases magistrales y las formulas tradicionales que suele llevar como fin el aprendizaje memorístico, debe dejar paso a la utilización de metodologías más innovadoras, en las que la participación del alumnado en el proceso de enseñanza-aprendizaje sea mayor. En este sentido, sin considerar que la explicación 
del profesorado tenga que ser erradicada, se apuesta por metodologías más innovadoras, en las que la interacción entre todos los miembros de la comunidad educativa sea mucho más intensa.

La competencia social y cívica consideramos que es una de las más complejas de desarrollar. Se justifica esta afirmación en que no sólo hace imprescindible una participación muy activa del profesorado y del alumnado, sino también de las familias y de agentes sociales del lugar donde se ejercita. En tanto que propicia el conocimiento del lugar y la sociedad en la que se reside, implica profundizar en cuestiones como son: su origen y dinámica socioeconómica y ambiental a lo largo del tiempo. Estas cuestiones son claves para entender no sólo la realidad actual, sus problemas y potencialidades, sino también para desarrollar destrezas que permitan ejercer los derechos y los deberes ciudadanos, así como conocer los cauces democráticos que existen para ejercerlos, tanto de forma individual como grupal.

Lo anterior anima a informarse, reflexionar, dialogar, a comprender que existen opiniones y valoraciones diferentes sobre un mismo tema, a consensuar soluciones posibles y actuar para tratar de cambiar realidades que no nos parezcan adecuadas. En definitiva a conocer la realidad que nos envuelve, a conocernos mejor a nosotros mismos cuando interactuamos con el entorno, a ser activo/a en la realidad que nos ha tocado vivir y ser protagonistas de su mejora.

Las familias sin duda, son en buena medida agentes importantes en los valores sociales y cívicos que tienen asumidos los discentes. A lo anterior se une que las conversaciones en los hogares sobre las tareas programadas en el curso, pueden ser un buen momento para reforzarlos, máxime cuando estas salidas del centro deben ser autorizadas por los padres y se suelen comentar en las reuniones periódicas que se tienen entre el profesorado y sus representantes legales. En tanto que las competencias sociales y cívicas pueden trascender los ámbitos familiares y del centro, se hace también preciso mantener conversaciones con las personas y/o autoridades que pudiesen ser afectados.

La oportunidad que ofrece el enorme patrimonio existente en nuestro país, consecuencia de la gran cantidad de pueblos que han pasado por el solar peninsular a lo largo de la historia, favorece el diseño de itinerarios didácticos en distintos niveles educativos. En el caso del municipio de Almuñécar, esta oportunidad es especialmente importante ya que, como se adelantó más arriba, se trata de un núcleo poblacional que fue fundado por los fenicios y constituye una de las ciudades andaluzas e incluso podría afirmarse que mediterráneas, más importante en cuanto al número y valor de los recursos patrimoniales que de aquel tiempo se conservan. 


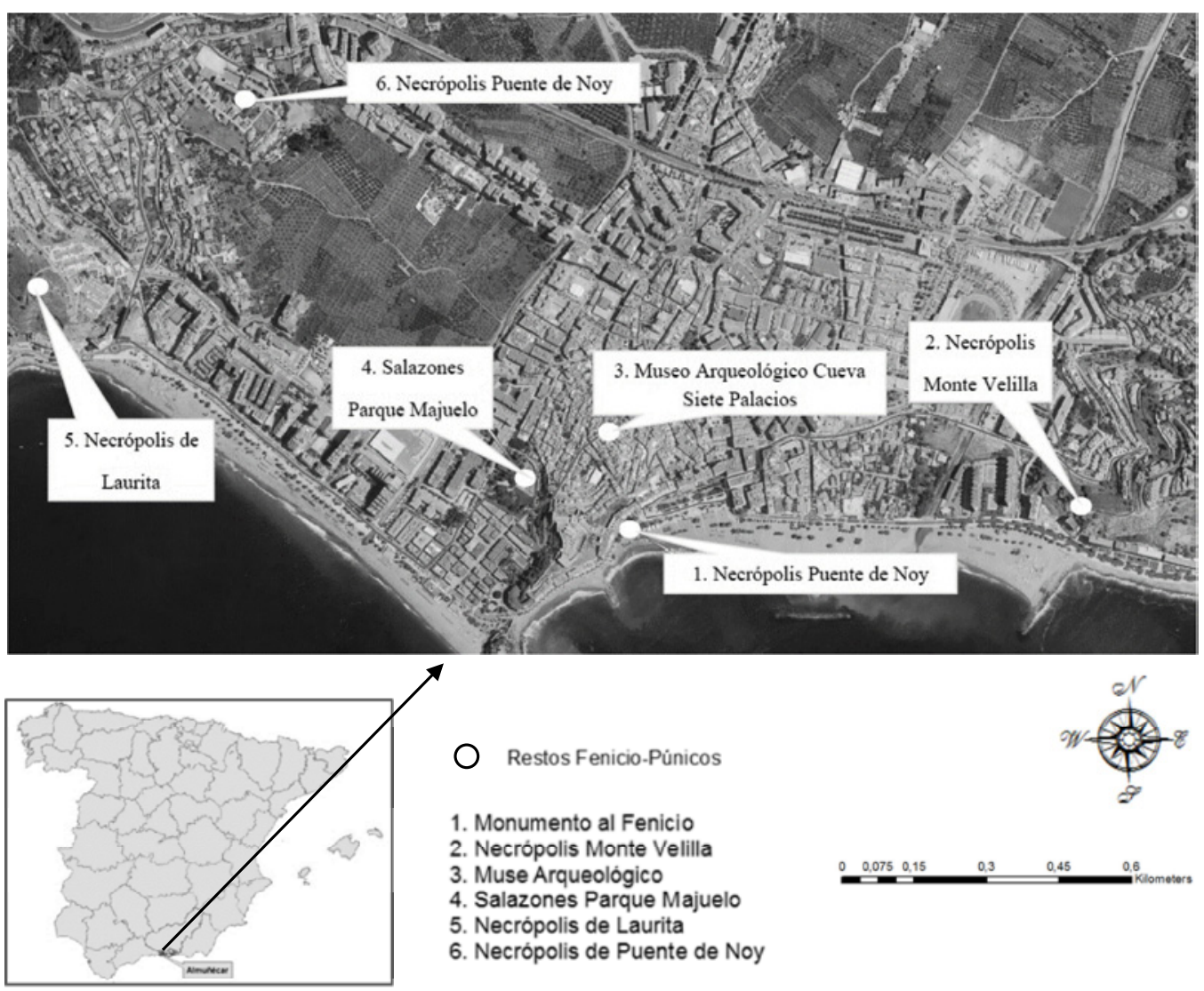

FiguRA $N^{\circ} 1$. Mapa de localización del municipio de Almuñécar y de los principales puntos clave del itinerario mediante el uso de la Ortofotografía del PNOA. Elaboración propia.

En la actualidad Almuñécar es la segunda ciudad más importante desde el punto de vista económico de la costa de Granada, reconociéndosele, precisamente por su enorme patrimonio histórico y sus playas, la condición de capital turística de la Costa Subtropical. Su singular clima subtropical permite, además de la obtención de una importante producción de chirimoyos, aguacates, mangos y otros frutos tropicales, que las actividades al aire libre puedan realizarse durante todo el año ya que no existe invierno térmico. Con una temperatura media de $18^{\circ} \mathrm{C}$, una baja amplitud térmica tanto diaria como anual propiciada por la influencia del mar Mediterráneo, la hace una ciudad especialmente valorada. De lo anterior se puede inferir que el itinerario didáctico se puede realizar en cualquier momento del año. 


\subsection{Características de las tres fases del itinerario y su desarrollo}

La preparación del itinerario se ha estructurado en tres fases. La primera que se ha dedicado a su diseño y preparación, una segunda donde se produce la ejecución y finalmente la tercera propicia la reflexión en el aula de las cuestiones tratadas en las fases anteriores. En ellas, siguiendo a Liceras (2018), se pretende nada menos que hacerles: identificar, inventariar, describir, comprender, relacionar, explicar, valorar, comparar, extrapolar, generalizar, disfrutar y responsabilizar.

\subsubsection{La primera fase o fase previa preparativa en el aula.}

El diseño y preparación comienza con la selección de los PID. La participación activa del alumnado es fundamental por lo que se les anima a que indiquen en el aula que recursos de origen fenicio conocen. Tras hacerlo de forma grupal, y ser recogidos en la pizarra, comparan sus resultados con los que han indicado sus compañeros/as, y con los contenidos en varias páginas web que el profesorado ha seleccionado previamente. La selección de los puntos de mayor interés didáctico vendrá dado por la importancia científica que le otorgan los estudiosos.

Los PID incluidos para su visita, pueden ayudar a que reflexionen y consensuen los parámetros más adecuados para ordenar el recorrido (¿cronológicos?, ¿contigüidad espacial?, ¿mayor a menor interés científico?, ¿circuito circular por lo que facilita la vuelta a un punto concreto donde sea más adecuado finalizar el recorrido?, etc.,), así como las normas a respetar durante su duración y las actividades a realizar por parte del alumnado en cada uno de los PID.

Esta actividad previa les va a permitir tanto comprobar su grado de conocimiento de este patrimonio de su ciudad, como empezar a tratar de localizar sobre un plano de la localidad de Almuñécar su situación, lo que facilitará captar su atención y animarles a hacerse preguntas como: ¿de dónde vinieron?, ¿cuándo vinieron?, ¿por qué decidieron asentarse aquí?, ¿a qué se dedicaban?, ¿cómo fue su relación con la población autóctona?, ¿qué conocemos de su organización política?, ¿qué sabemos de su organización económica?, ¿cómo era su organización social?, ¿cuáles eran sus creencias religiosas?, etc.

La lectura del tema "Los cauces de relación de Andalucía con las civilizaciones mediterráneas: colonizaciones fenicias y griegas" de $1^{\circ}$ de ESO, les va a proporcionar las claves para situar la colonización de Almuñécar tanto cronológicamente como espacialmente. Estas cuestiones, junto con la solicitud a sus familiares y conocidos que respondan a un breve cuestionario sobre lo que conocen sobre la presencia de los fenicios en la ciudad (¿cuándo llegaron?, ¿dónde se asentaron en la ciudad?, ¿qué restos conocen de aquella época y consideran los más destacados?), les van a preparar para 
que se interesen por su conocimiento y por el estado del patrimonio que nos legaron. Se completará este primer acercamiento con la visualización del pequeño, pero didáctico vídeo titulado: "Los Fenicios, el Mediterráneo y el comercio marítimo", accesible de manera gratuita a través de la plataforma YouTube, permitirá que tengan una visión general de este pueblo, en poco más de 11 minutos.

Lo anterior se acompañará con un cuaderno de campo común para el alumnado, y otro para el profesorado, cuya estructura será explicada de manera razonada al conjunto de la clase. El cuaderno tendrá como finalidad orientar las cuestiones claves que deben trabajar, realizar y responder en cada uno de los PID (Tabla 1). Contendrá una serie de actividades a completar por parte de cada grupo (conformado por 4 alumnos) y el espacio necesario para tomar notas sobre las respuestas que cada grupo haya recogido en el PID que haya trabajado. El cuaderno del profesorado incluye las cuestiones clave que deberá tener en cuenta y explicar en cada PID.

Sobre este particular, para un grupo extenso de 24 alumnos, se ha considerado adecuado conformar seis grupos reducidos, uno por cada PID seleccionado. Cada miembro, aunque tenga una responsabilidad compartida en el trabajo, tanto propio como de recogida de la información relevante que presenten el resto de los grupos en el recorrido, deberá asumir unas obligaciones específicas de las que dará cuenta.

El grupo ha de ir unido, bajo ningún concepto, salvo permiso expreso del profesorado, ninguna persona se aleja del grupo. En el PID deben situarse alrededor de quien/es hablen, y tendrán preparados sus materiales para explicar al resto de grupos sus investigaciones guiadas. Cada grupo tendrá preparado su cuaderno para tomar notas sobre las cuestiones claves de cada PID.

Sobre la organización y funcionamiento de los grupos elegidos al azar, uno de ellos se encargará especialmente de las cuestiones de recopilación de las informaciones históricas (arqueológicas) clave de cada PID. Otro se ocupará de las cuestiones instrumentales y esencialmente geográficas. Un tercero se responsabilizará de realizar las fotografías que muestren el grado de acceso, conservación y protección del recurso patrimonial. Finalmente, el cuarto realizará las labores de cumplimentación del cuestionario del cuaderno y exposición de los contenidos resultantes en el recorrido ante el resto de grupos.

Entre las cuestiones que se deberán explicitar en la sesión de preparación del itinerario, son los medios que deberán llevar. En el caso de este itinerario didáctico, se hace imprescindible que cada grupo lleve ropa y calzado cómodo, un Smartphone para realizar fotografías y poder tomar las coordenadas geográficas del lugar, la orientación, y captar elementos clave del paisaje que se puede visualizar desde cada PID. También utilizará la aplicación Google Maps para fijar el recorrido y de esta manera saber 
perfectamente las calles por donde se va a transitar, así como la distancia recorrida. En este sentido, como afirma Alcántara, J. y Medina S. (2018), la utilización de SIG, constituye un instrumento muy valioso para la educación y para el diseño de itinerarios.

Elegidos los seis PID citados con anterioridad, se procede a informar al alumnado sobre el horario de salida (que coincidirá con la hora de entrada al centro), la secuencia del recorrido que seguirá el criterio cronológico, salvo en el caso del primer punto de interés turístico (Monumento al Fenicio) que se justificará en su momento. El profesorado también deberá realizar las gestiones indispensables para poder acceder gratuitamente al Museo Arqueológico Cueva de los Siete Palacios.

El tiempo estimado de duración es de una jornada normal de un centro, con inicio a las 8:15 horas y finalización a las 14:45 horas, es decir seis horas y media. El recorrido programado tiene una longitud de $3,3 \mathrm{Km}$ y el desnivel medio que hay que sortear es reducido. Se realizará andando ya que discurre a través de las calles de la ciudad, no siendo necesario utilizar ningún medio de transporte urbano. La duración por cada PID será de 1 hora aproximadamente, incluyendo desplazamientos. Se ha procurado que sea lo más accesible posible teniendo en cuenta al alumnado con discapacidades. Tras la finalización del trayecto, todos se dirigirán al centro de estudios del que han partido.

\subsubsection{La segunda fase. Salida de campo, ejecución del itinerario.}

La salida de campo se realizará en torno al mes de mayo. Se establecen un total de seis PID, que siguen un orden cronológico y que quedan recogidas en la cartografía elaborada para este itinerario didáctico a través de un SIG (Figura 2).

En esta fase se realizará una exposición breve sobre aspectos relevantes de cada PID. Mediante esta actuación el alumnado deja de ser un sujeto pasivo y la salida de campo no se convierte en una mera excursión, sino que se configura en parte fundamental del proceso de enseñanza-aprendizaje. Esto refuerza la idea del uso de la cartografía en la aplicación de los itinerarios didácticos, como dice Sancho Comís (1996), las nuevas tecnologías afirman el valor indiscutible del mapa como recurso didáctico.

El alumnado en esta fase tendrá que asumir labores tanto de exposición de su trabajo, escucha activa y realización de entre otras actividades, obtención de fotografías de los PID que no haya trabajado, sus coordenadas geográficas, tomará su altitud, orientación, tomará notas sobre la cronología, sobre las características y funcionalidad de los recursos, sobre su importancia científica, sobre el uso que tiene en la actualidad y el estado de conservación/protección en que se encuentran. La recopilación de toda esta información en los respectivos cuadernos de campo por parte de cada grupo y para cada PID, será de vital importancia para lograr como producto final la redacción de una carta grupal reivindicativa dirigida a las instituciones responsables del patrimonio local. 


\subsubsection{La tercera fase. Reflexión y conclusiones.}

La sesión post visita se realizará en el aula ordinaria e irá destinada exclusivamente a la reflexión sobre el itinerario realizado y a búsqueda de conclusiones. Se reflexionará sobre los contenidos tratados, su historia local, la importancia de la Geografía y de la Historia para interpretarlos, estado de conservación actual de los restos fenicios, transmitir ideas, elaborar propuestas o medidas de protección que se podrían llevar a cabo, intercambiar opiniones e incluso debates sobre las razones que se presentan para consensuar las más oportunas.

Esta última sesión es fundamental, ya que como afirma Gonçalves, Corrochano y Parra (2017), tras la finalización del itinerario, se mejorarán los resultados de aprendizaje realizando diferentes actividades en el aula que afiancen los contenidos trabajados. En este sentido, se obtendrán las conclusiones generales del itinerario didáctico a través de un análisis de toda la información recogida en los cuadernos de campo para cada PID. Los discentes deberán debatir sobre si se hace o no preciso escribir una carta reivindicativa a las autoridades locales para mejorar las condiciones en que se encuentra el patrimonio fenicio del municipio de Almuñécar.

En el caso de que el resultado sea positivo, la carta reivindicativa y documentada con fotografías mostrará el estado de abandono de los restos fenicios y solicitará su protección, así como la necesidad de ponerlos en valor, a fin de que se tengan en cuenta por parte de los técnicos municipales y autoridades políticas responsables de los diferentes ámbitos administrativos, de su acceso, conservación y restauración. Entre todos se consensuarán las razones clave que justifican la intervención por parte de las autoridades, seleccionarán las pruebas documentales y planificarán los medios para asegurarse de que les llega su carta y para asegurar una respuesta a sus demandas.

\section{DESCRIPCIÓN DEL ITINERARIO DIDÁCTICO POR LA LOCALIDAD DE ALMUÑÉCAR. CUESTIONES A TRABAJAR POR PARTE DELALUMNADO}

\subsection{Descripción de la localidad de Almuñécar}

Almuñécar es una ciudad costera de la provincia de Granada, con una extensión superficial de $83,3 \mathrm{~km}^{2}$ y con una población de 26.377 habitantes (INE, 2018). Su origen fenicio está constatado por los restos arqueológicos documentados y los numerosos estudios científicos que se han llevado a cabo en el municipio durante décadas. Algunas investigaciones afirman que ya por el 1500 a. C. existía presencia de población, lo que se corresponde con la Edad del Bronce y la cultura argárica. A finales del s. IX a. C., su origen y fundación se atribuye a los fenicios bajo la denominación de Ex, posteriormente Sexs o con los romanos (siglo III a. C.) Firmum Iulium Sexi, lo que marca el punto de partida de la importancia que tuvo esta ciudad 
para los fenicios y sus relaciones comerciales con el Mediterráneo, así como para las civilizaciones venideras.

Los primeros relatos históricos de la localidad se remontan al geógrafo e historiador griego Estrabón. En su obra, Geografía de Iberia, de gran reconocimiento mundial, uno de los pasajes menciona la localidad de Sexs (Almuñécar), fundada por los fenicios, y su importancia como ciudad portuaria y mercante de la costa. Cabe destacar también las fuentes escritas que citaron a la ciudad fenicia de Sex, como fue el caso de Hecateo de Mileto, Difilo de Sínope, Plinio el Viejo, Tito Livio, Ptolomeo, etc. (Pastor, 1983; 2000). Todas confirman la gran importancia que tuvo la ciudad en el contexto de las ciudades fenicias mediterráneas.

Lo encontrado en Laurita permite afirmar que al menos desde la segunda mitad del siglo VIII a.C. o siglo IX a. C está confirmada la presencia de un importante asentamiento fenicio (Mederos y Ruíz, 2002). Del mismo modo, parece aceptada la teoría de que tras un largo periodo precolonial, basado en relaciones comerciales con las poblaciones locales de la Edad del Bronce, los fenicios se decidieron a instalar las primeras factorías en el siglo VIII a C. en nuestras costas andaluzas (Bravo, 2000; Adroher, A y Cobos, A, 2007; Arribas, 2009) presionados por la expansión militar del Imperio Asirio.

La mayor parte de la información que disponemos sobre los fenicios en Almuñécar proviene de diversos estudios científicos que se han basado en las evidencias proporcionadas por las excavaciones arqueológicas realizadas en el municipio, desde los primeros años de la década de los sesenta por Manuel Pellicer, fallecido recientemente en abril de 2018, en las necrópolis fenicio-púnicas de Laurita (Pellicer, 1963, 1985, 2007), a las que siguieron otras publicadas por Molina Fajardo, en la década de los ochenta, sobre la Necrópolis de Puente Noy y la Necrópolis de Cerro de Velilla.

Las distintas intervenciones arqueológicas realizadas en las últimas décadas, tales como, las acometidas por (Pellicer, 1963) en la ladera oeste del Castillo, (Sotomayor, 1971) en el parque del majuelo, (Molina, 1982, 1984, 1986) en la Cueva de Siete Palacios, Calle Real con derrumbadero, Plaza de la Constitución, Palacete del Corregidor, la zona del Hotel "Carmen", Calle Vélez no 3, excavación de una tumba fenicio-púnica en el entorno de "La Cerca"; han documentado abundantes materiales arqueológicos que nos hablan de un asentamiento de importancia, aunque por el momento no parece haberse documentado restos de edificaciones de la ciudad fenicia. Por el contrario, los lugares de enterramiento si están bien documentados con la localización de las tres necrópolis citadas: Montevelilla, Laurita y Puente de Noy.

En definitiva, el emplazamiento de esta población parece responder a los patrones fijados para la instalación de factorías comerciales, ya que hay que tener en cuenta que los promontorios sobre los que se asienta la ciudad formaban entonces una península, 


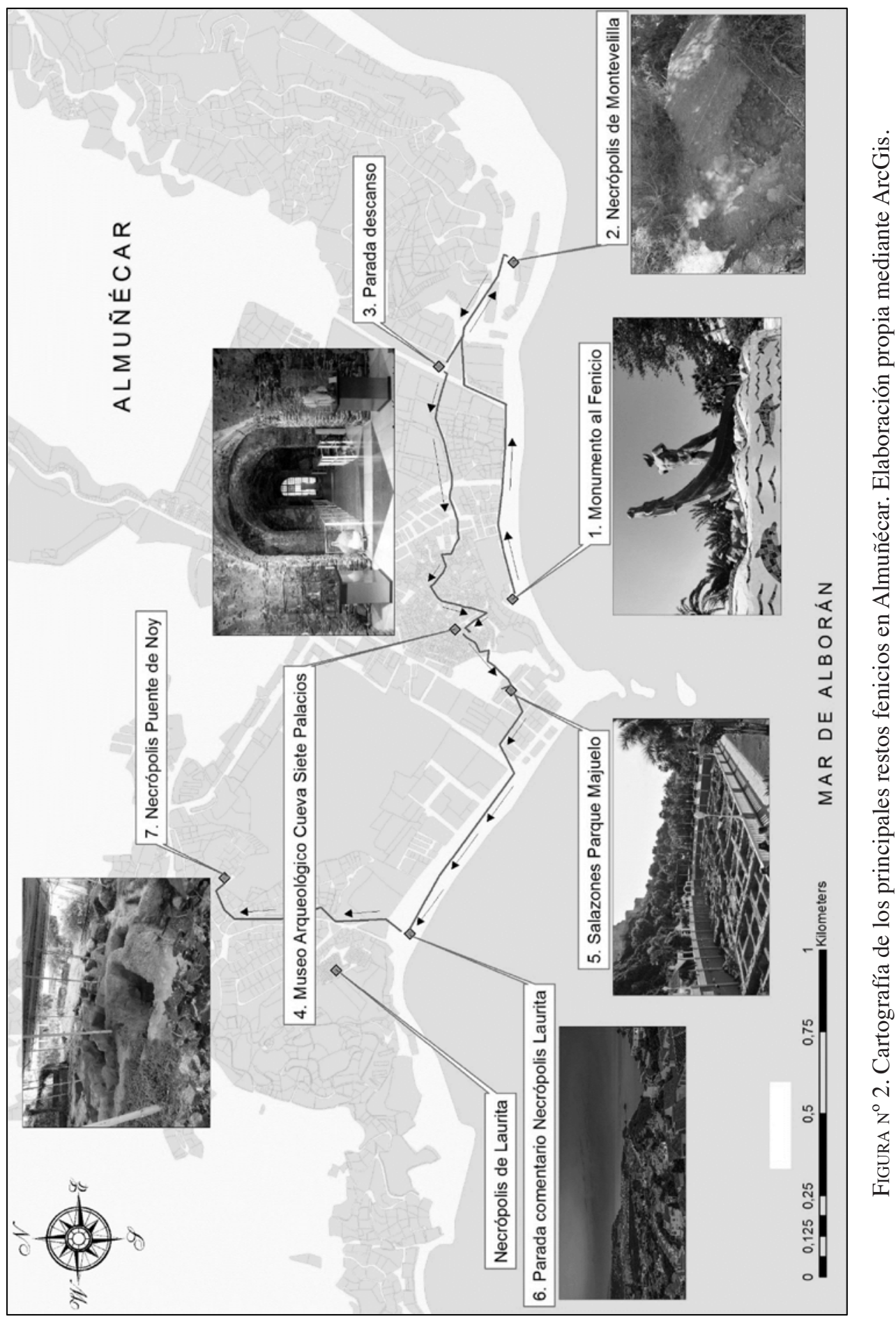


mientras que el cerro de San Cristóbal se encontraba completamente rodeado por el mar. Por otro lado, existen otros factores que otorgan singularidad a estos asentamientos fenicios. Según Sánchez (2013, p. 147-148), es preciso tener en cuenta la localización geográfica del municipio sexitano a orillas del mediterráneo, ya que esto justifica su desarrollo portuario a partir de la cual dar salida a todo tipo de producción salazonera, muy valiosa y codiciada en el mediterráneo.

\subsection{Descripción de los Puntos de Interés Didáctico (PID)}

En este apartado se fundamenta la elección de los recursos históricos fenicios incluidos en el itinerario didáctico, resaltando su valor didáctico, histórico y patrimonial. Para lograr dicha fundamentación recurrimos a una extensa bibliografía disponible sobre los restos fenicios de Almuñécar. Los que se van a analizar, con excepción del inicio del itinerario donde presenciaremos una escultura contemporánea en homenaje a los fenicios como fundadores de la ciudad de Sex, se corresponden con restos de época argárica y de la Edad del Bronce, constituidos por pequeños asentamientos y varias necrópolis poco conocidas en la actualidad.

\subsubsection{Primer punto de interés didáctico: Monumento al fenicio}

La estatua en bronce hace homenaje a los fenicios como fundadores de la ciudad de Almuñécar (Sex). Se localiza en el Paseo del Altillo, frente a la playa de Puerta del Mar, y fue realizada por el escultor y orfebre granadino Miguel Moreno Romera, en 1987.

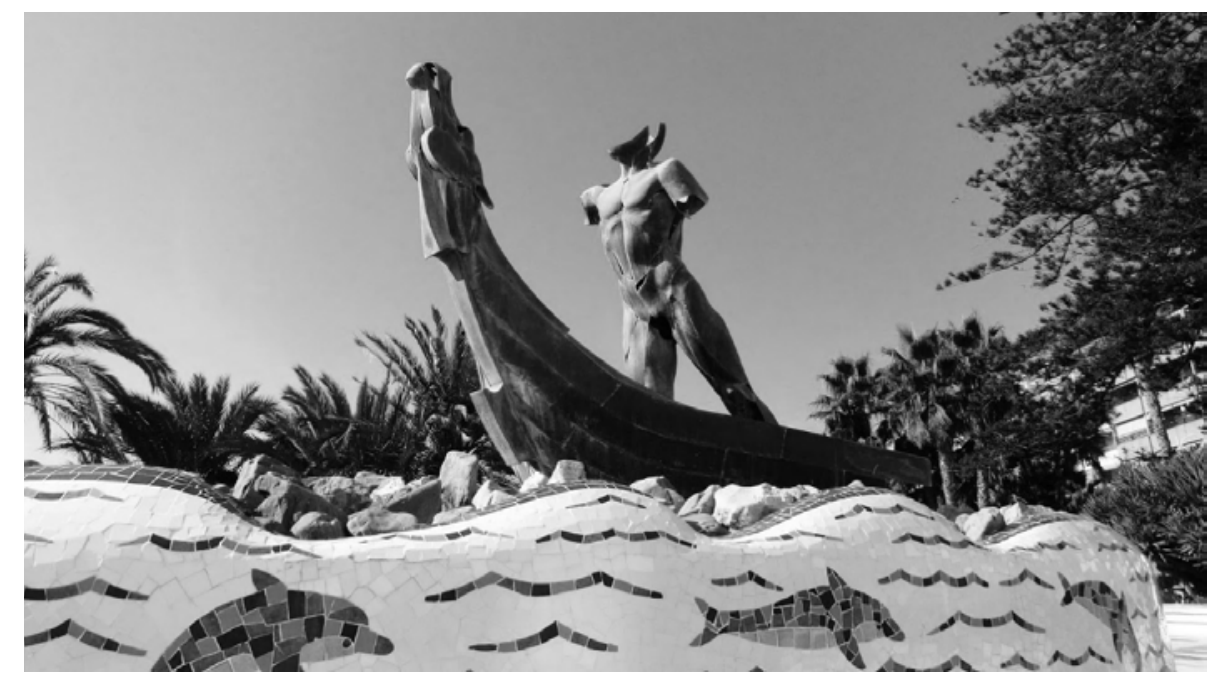

FIGURA N ${ }^{0}$ 3. Monumento en homenaje a los fenicios. Elaboración propia. 
Los fenicios ocuparon esta zona del Mediterráneo en el siglo VIII a.C. Para esta cultura el mar era su principal fuente económica y fueron los mejores navegantes de la época. El monumento se presenta como una figura anónima, un fenicio musculado que se encuentra sobre un barco, conocido como "hippoi". Era un tipo de barco fenicio construido con madera de cedro del Monte Líbano. El desconocimiento de la brújula implicaba que la navegación debía realizarse en horarios diurnos, con la luz solar y bordeando las costas. Eran embarcaciones de carácter ligero, rápidas y fáciles de maniobrar propulsadas mediante remo y vela. Estos barcos podían remontar ríos con facilidad y acceder a zonas de escasa profundidad como en el caso de Sex.

\subsubsection{Segundo punto de interés didáctico: Necrópolis de Montevelilla}

La necrópolis de Montevelilla ha sacado a la luz numerosos objetos de gran valor histórico y patrimonial, lo que pone de manifiesto la importancia de este enclave geográfico para la sociedad fenicia del momento. En los años sesenta del siglo XX se produjo la noticia de un hallazgo importante en la zona de Monte Velilla. Según Pellicer (2007), un vecino de la zona había encontrado un colgante de oro en forma de "U" que fue catalogado de origen fenicio. Junto a este hallazgo aparecieron más objetos que datan del s. VI a.C.

El descubrimiento más reciente ha sido un enterramiento de un hombre y una mujer acompañada de urna funeraria y ánfora de cerámica. La evidencia documentada en esta campaña presenta un tipo de necrópolis que no se corresponde con ninguno de los dos casos hasta ahora conocidos en el entorno de Sex, pues no son enterramientos en fosas profundas, sino que parecen muy superficiales, donde cada uno de los contenedores excavados presenta restos de individuos cremados, y sin ajuar añadido. (García, et al., 2018, p. 94).

El PID se sitúa en los alrededores de una necrópolis fenicia, donde destacan las fosas excavadas en la zona y su observación permite concienciar al alumnado sobre el grado dejadez, deterioro y abandono del lugar. Se trata de un lugar clave para conocer los cambios que surgieron en torno a los ritos funerarios fenicios que se llevaban a cabo en esta zona. Tal como afirmó Pellicer (2007), el rito fenicio de la incineración, adoptado y conservado en el orientalizante e ibérico del interior peninsular, será sustituido por el de la inhumación hacia el s. VI a.C. en las necrópolis púnicas de la costa (Villaricos, Velilla, Puente de Noy, Jardín, Cádiz, Isla Palomas de Tarifa).

En definitiva, desde este PID es posible visualizar la línea de costa e imaginar cómo los fenicios podían controlar desde estas ubicaciones en altura la ciudad fenicia de Sex. También "se perciben perfectamente las otras dos necrópolis fenicias, la de Puente de Noy y Cerro de San Cristóbal, comprendiéndose a la perfección la relación orográfica, 
El desarrollo de las competencias sociales y cívicas en Ciencias Sociales: itinerario didáctico...

territorial y paisajística en la distribución hábitat-necrópolis durante la ocupación semita" (García, et al., 2018, p. 94).

\subsubsection{Tercer punto de interés didáctico: Museo Arqueológico Cueva Siete Palacios}

En este PID se visita el museo de Cueva Siete Palacios, situado en el Cerro de San Miguel y sede desde 1984 del actual museo arqueológico municipal de Almuñécar. Este espacio dispone de todo tipo de cerámicas púnicas, objetos, figuras, monedas, vasos de alabastro, ajuares, joyas y materiales de la factoría de salazón.

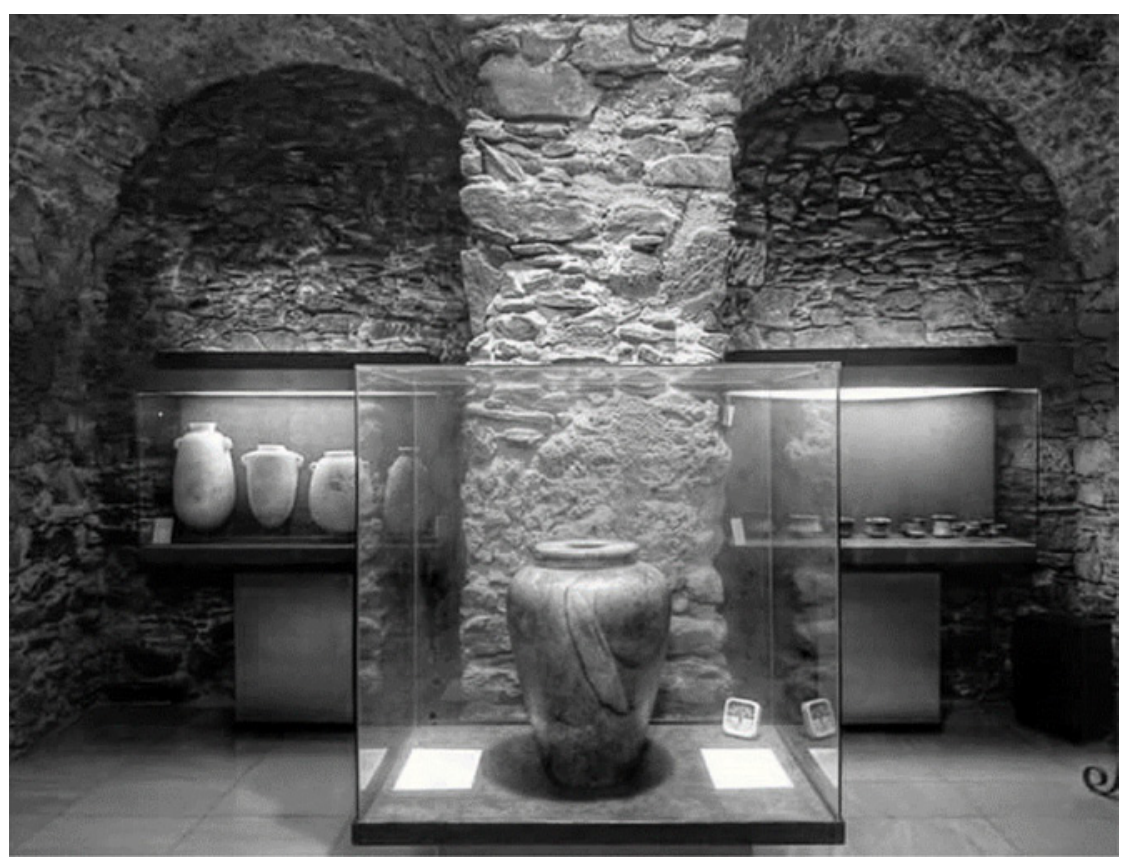

FIGURA $\mathrm{N}^{\mathrm{O}}$ 4. Vaso egipcio del Emperador Apofis I en el museo arqueológico Cueva Siete Palacios de Almuñécar. Elaboración propia.

La gran pieza estrella que alberga este museo es un bello vaso egipcio de la época del faraón Apofis I del S. XVII a. C. Este vaso fue trasladado por los navegantes fenicios en una de sus rutas comerciales por el mediterráneo hasta la localidad de Sex. Es de mármol y dispone de una escritura jeroglífica con forma de sello donde aparece el nombre del faraón Apofis I. El vaso egipcio fue encontrado en las excavaciones que se realizaron en la Necrópolis de Laurita. Recientemente, esta pieza ha sido expuesta en el Metropolitan Museum de Nueva York. 
En las campañas de excavación de los años ochenta del siglo XX, se pudo documentar una secuencia cultural en el interior de esta cueva, donde destacó la presencia de un hábitat del bronce final, fenicio, púnico e ibérico. Como recoge Pellicer (2007), Molina Fajardo efectuó una serie de sondeos y cortes estratigráficos de urgencia en diferentes puntos del núcleo urbano antiguo de Almuñécar, a través de los cuales es posible delimitar el perímetro del establecimiento fenicio y púnico y determinar la cronología de la evolución del yacimiento.

\subsubsection{Cuarto punto de interés didáctico: Factoría de los Salazones Parque del Majuelo}

El siguiente PID se sitúa junto a las laderas del Castillo de San Miguel, en la factoría de Salazones del hoy Parque Botánico El Majuelo. Para Molina y Jiménez (1983) se trata de un lugar singular como centro de producción y de actividad comercial. Los autores afirman que los restos encontrados en esta factoría de salazones han permitido constatar que se trata de un lugar con una cronología que abarca desde el siglo I a. C a finales del IV d. C o principios del V d. C.

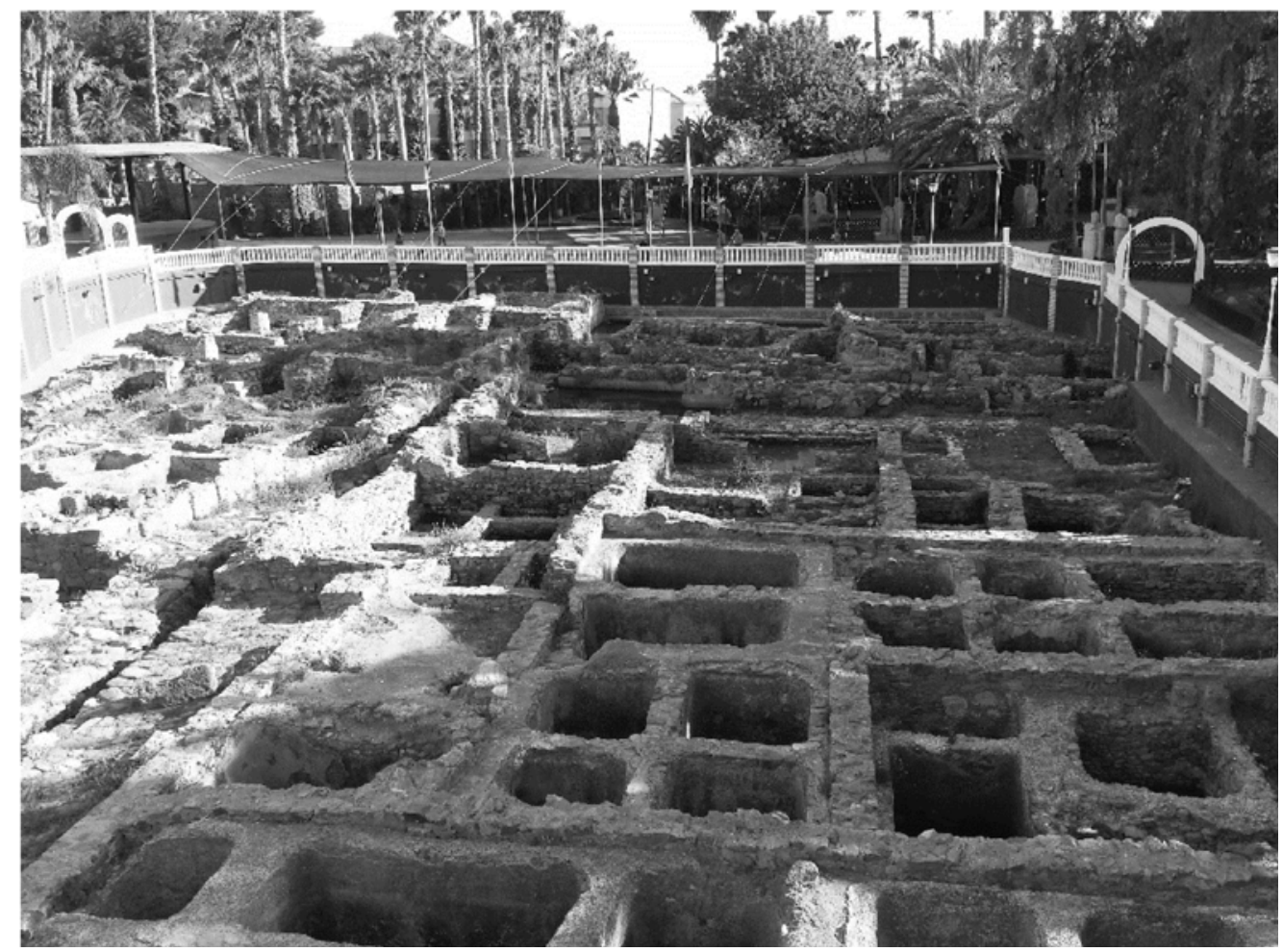

FIgura N ${ }^{0}$ 5. Factoría Salazones en el Parque el Majuelo de Almuñécar. Elaboración propia. 
La gran cantidad de material extraído de esta zona ha aportado información de vital importancia para conocer el pasado de este lugar. También, según Molina y Jiménez (1983), han permitido estudiar otros aspectos como la importancia de las rutas comerciales, los centros de producción o las exportaciones e importaciones de productos alimenticios básicos. Sierra (2009) afirma que estos aspectos le dieron un impulso muy fuerte a la ciudad de Sexi y la convirtieron en un centro de gran actividad económica en el Mediterráneo.

Las primeras noticias sobre la localización de las factorías de salazón de Almuñécar se remontan a los años 70 del siglo XX. Las campañas de excavación que se realizaron en diversas zonas del núcleo urbano fueron muy intensas. En el caso de El Majuelo, destacan las excavaciones realizadas por Manuel Sotomayor y Enrique Pareja. Lamentablemente, años más tarde, muchos de estos restos fueron enterrados para la construcción del actual Parque Botánico El Majuelo. Las excavaciones y sondeos que se realizaron por parte del equipo de Molina Fajardo han documentado la existencia del primer asentamiento fenicio del siglo VIII a. C.

\subsubsection{Quinto punto de interés didáctico: Necrópolis de Laurita}

La necrópolis de Laurita se sitúa en el Cerro de San Cristóbal. En el año 1962 se comenzó a construir en el Cerro de San Cristóbal el popular barrio de Los Marinos, para los pescadores del municipio. Tras el avance de las obras, los restos cerámicos y ajuares funerarios de orfebrería, incluido el vaso egipcio, entre otros, eran una constante.

El saqueo de las tumbas fue intenso y el deterioro de las mismas elevado, con restos de ajuares cerámicos de barniz rojo dispersos y fragmentados. Hoy conocemos que dispone de 22 enterramientos de incineración con urnas de alabastro. Según las investigaciones de Pellicer (2007), puede que se trate de un conjunto de enterramientos pertenecientes a una limitada clase social alta, quizás a una élite prestigiosa de los primeros colonos de Sex, y, por otra parte, a que su encuadre cronológico corresponde como máximo, a tres cuartos de siglo, equivalente a tres generaciones.

El descubrimiento de esta necrópolis puso de moda la feniciomanía, ya que supuso un hito importante sobre los fenicios e impulsó las investigaciones arqueológicas sobre el mundo fenicio occidental ibérico. La necrópolis se encuentra dentro de una finca privada lo que dificulta el acceso a la misma. El propietario de la década de los sesenta permitió el acceso de Pellicer para realizar las excavaciones pertinentes.

\subsubsection{Sexto punto de interés didáctico: Necrópolis de Puente de Noy}

La Necrópolis de Puente de Noy se localiza al oeste del río Seco, en la colina donde se sitúa el IES Antigua Sexi. Fue descubierta por un profesor de instituto en 1979. 
Posteriormente se iniciaron campañas de excavación por parte de F. Molina Fajardo y su equipo y, ya en el año 1982, se dio a conocer la necrópolis fenicio-púnica de Puente de Noy. Este hallazgo, tras el de Laurita, volvía a poner de manifiesto la importancia de la colonización fenicia en Almuñécar, corroborando lo que afirmaban las fuentes escritas de la época, que citan a Sexi como una de las colonias fenicias más destacadas del Mediterráneo hispano (Molina y Huertas, 1985).

Se trata de un PID de especial interés, ya que en la zona se excavaron un total de 102 tumbas púnicas de inhumación, con gran variedad de tipos de ajuares y un amplio abanico cronológico que va desde el S. VII hasta el I a. C.

En la Figura 6 puede observarse una parcela que alberga gran cantidad de tumbas de origen fenicio. Las imágenes fueron tomadas en junio de 2019, participando en las Jornadas Arqueológicas que se llevaron a cabo en la Necrópolis de Puente Noy.

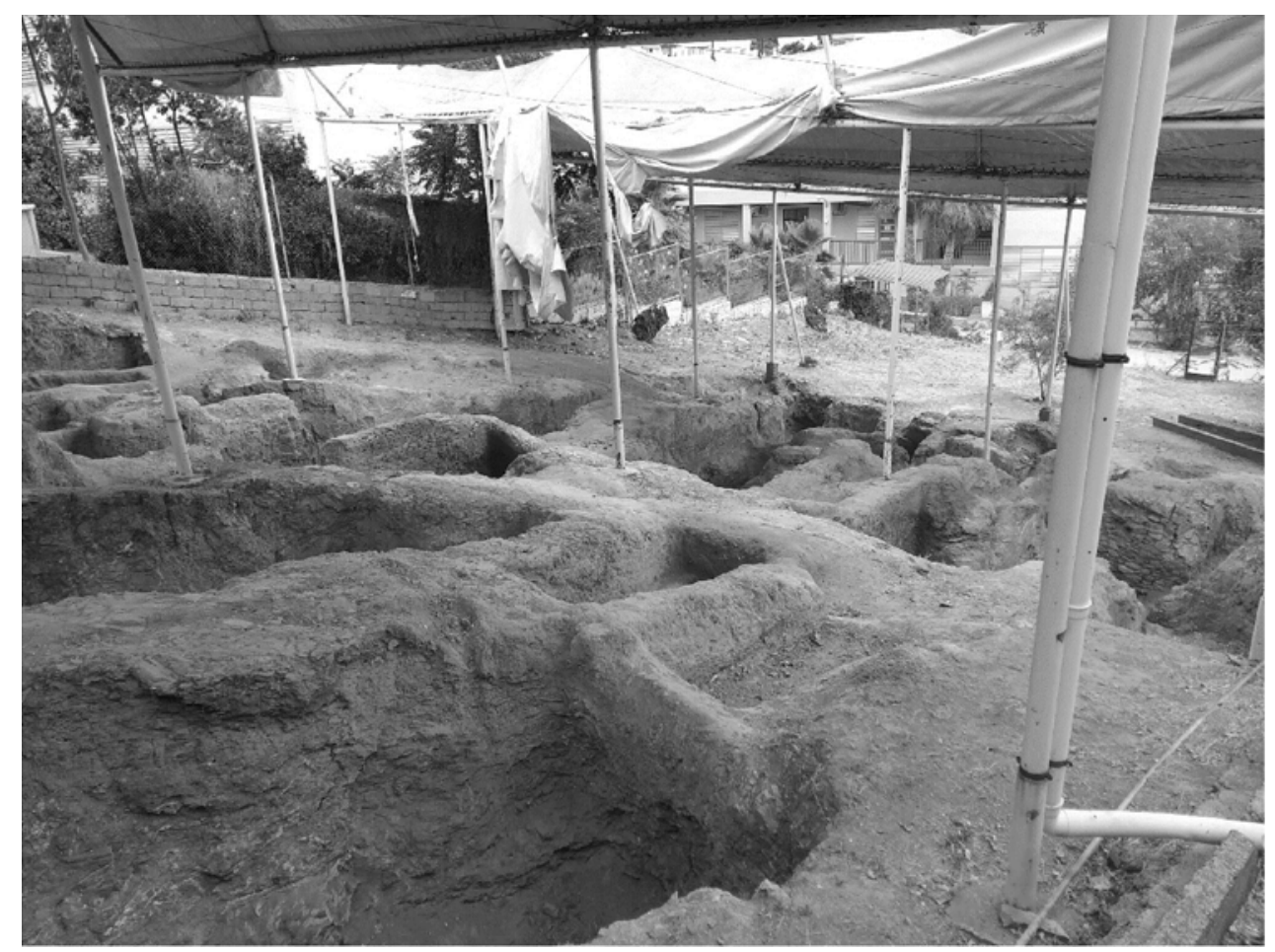

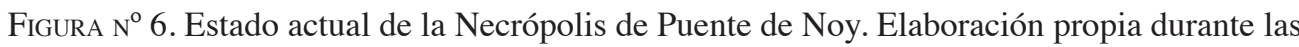
Jornadas de Arqueología celebradas en junio de 2019.

Debemos otorgar especial importancia a la gran tumba denominada E-1, la de mayor tamaño del lugar y cuyo gran pozo de planta de tendencia rectangular mide $5,60 \mathrm{~m}$ por 
$5,20 \mathrm{~m}$, con una profundidad de 7,50m, excavado en la roca, con escalinata circundante (Pellicer, 2007), tal como muestra la Figura 7. Así mismo, esta tumba representa cambios de tipo social, religioso y funerario, donde la incineración en urna es reemplazada por la inhumación.

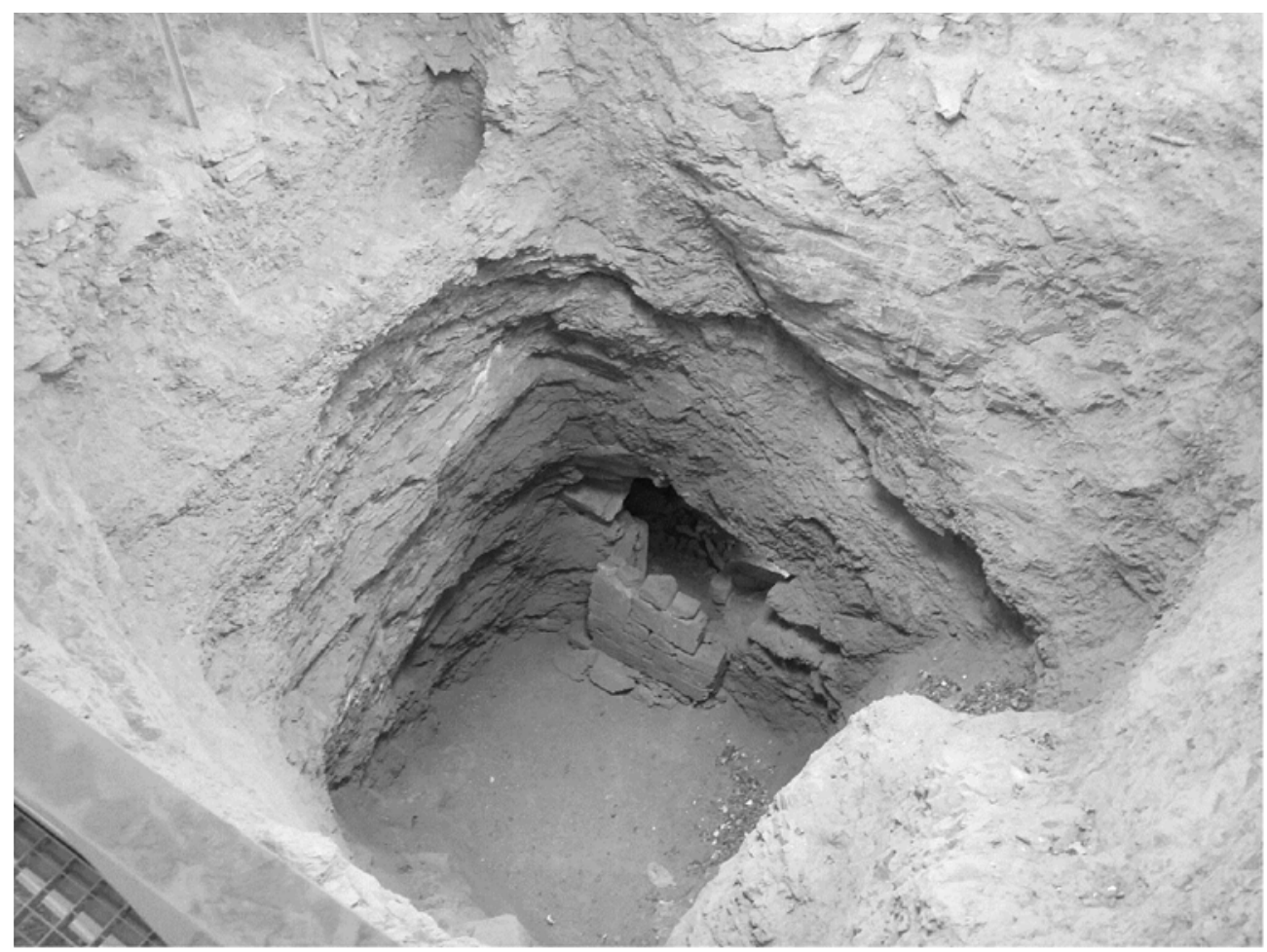

Figura $N^{0}$ 7. La gran tumba fenicia E-1 de la Necrópolis de Puente de Noy. Elaboración propia durante las Jornadas de Arqueología celebradas en junio de 2019.

Según Molina y Huertas (1984), la tumba E-1, excavada en 1981, estaba totalmente saqueada, en cuyo relleno aparecieron numerosos fragmentos de cerámica fenicia correspondiente a platos, copas y cuencos, como residuos de ritos funerarios.

\subsection{Cuestiones a trabajar por parte del alumnado en cada PID}

Sin haberse pretendido, en cada uno de los PID, se trabajan las siete competencias clave. Se resumen en la Tabla 1, los contenidos a trabajar, informaciones a recoger in situ, las principales reflexiones de interés que se tratarán, así como las competencias clave que en mayor o menor medida se trabajarán. 


\begin{tabular}{|c|c|c|c|}
\hline PID & Denominación & Contenidos y actividades del cuaderno de campo & $\begin{array}{c}\text { Competencias } \\
\text { clave a } \\
\text { trabajar }\end{array}$ \\
\hline $\begin{array}{l}\text { Primer } \\
\text { PID }\end{array}$ & $\begin{array}{l}\text { Monumento al } \\
\text { fenicio }\end{array}$ & $\begin{array}{l}\text { Ejemplo de reconocimiento del municipio a los } \\
\text { fundadores de la ciudad, que procedentes del } \\
\text { Mediterráneo Oriental, se asentaron en la costa de } \\
\text { Granada, entre los siglos VII al siglo I a. C. siendo la } \\
\text { actual Almuñécar su principal emplazamiento. } \\
\text { Cronología, coordenadas, altitud, orientación, } \\
\text { características. } \\
\text { Valorar el estado de conservación/protección. } \\
\text { Fotografías. } \\
\text { Localizar en Google Maps las costas orientales del } \\
\text { Mediterráneo (Líbano, Israel, Siria) comparar las } \\
\text { localizaciones de estas ciudades respecto a la costa } \\
\text { de Granada. } \\
\text { Describir lo que es un hippoi. } \\
\text { ¿El mar es una frontera o una gran autopista? Razona } \\
\text { tu respuesta. }\end{array}$ & $\begin{array}{l}(\mathrm{CCL}) \\
(\mathrm{CSC}) \\
(\mathrm{CMCT}) \\
(\mathrm{CD}) \\
(\mathrm{CAA}) \\
(\mathrm{SIEP}) \\
(\mathrm{CEC})\end{array}$ \\
\hline $\begin{array}{l}\text { Segundo } \\
\text { PID }\end{array}$ & $\begin{array}{l}\text { Necrópolis de } \\
\text { Montevelilla }\end{array}$ & $\begin{array}{l}\text { Cronología, coordenadas, altitud, orientación, } \\
\text { características, funcionalidad estratégica de control } \\
\text { territorial. } \\
\text { La importancia de los enterramientos para conocer } \\
\text { sus creencias, el grado de nivel técnico de las } \\
\text { sociedades. } \\
\text { Describe e investiga, incluso preguntando a } \\
\text { tus familiares y amigos, su estado de acceso/ } \\
\text { conservación/protección. }\end{array}$ & $\begin{array}{l}(\mathrm{CCL}) \\
(\mathrm{CSC}) \\
(\mathrm{CMCT}) \\
(\mathrm{CD}) \\
(\mathrm{CAA}) \\
(\mathrm{SIEP}) \\
(\mathrm{CEC})\end{array}$ \\
\hline $\begin{array}{c}\text { Tercer } \\
\text { PID }\end{array}$ & $\begin{array}{c}\text { Museo } \\
\text { Arqueológico } \\
\text { Cueva Siete } \\
\text { Palacios }\end{array}$ & $\begin{array}{l}\text { Cronología, coordenadas, altitud, orientación, } \\
\text { características. } \\
\text { La ceca fenicia de la ciudad. La primera serie } \\
\text { contiene símbolos púnicos (SKS, entre dos atunes en } \\
\text { el reverso). } \\
\text { Valorar la actividad comercial por las ciudades del } \\
\text { Mediterráneo. } \\
\text { Dibujar las rutas comerciales de los fenicios y } \\
\text { determinar las ciudades fenicias en el Mediterráneo. } \\
\text { Describir el estado de conservación/protección de } \\
\text { este patrimonio fenicio en el museo. }\end{array}$ & $\begin{array}{l}(\mathrm{CCL}) \\
(\mathrm{CSC}) \\
(\mathrm{CMCT}) \\
(\mathrm{CD}) \\
(\mathrm{CAA}) \\
(\mathrm{SIEP}) \\
(\mathrm{CEC})\end{array}$ \\
\hline
\end{tabular}




\begin{tabular}{|c|c|c|c|}
\hline $\begin{array}{c}\text { Cuarto } \\
\text { PID }\end{array}$ & $\begin{array}{c}\text { Factoría de } \\
\text { los Salazones } \\
\text { Parque del } \\
\text { Majuelo }\end{array}$ & $\begin{array}{l}\text { Cronología, coordenadas, altitud, orientación, } \\
\text { características. } \\
\text { La actividad económica más importante de los } \\
\text { fenicios fue el comercio a lo largo de diferentes } \\
\text { ciudades del mediterráneo y entre lo que } \\
\text { comerciaron estaba, la salazón de pescado (garum). } \\
\text { Investiga cómo se fabricaba y la importancia del } \\
\text { patrimonio fenicio. } \\
\text { Describir el estado de conservación/protección del } \\
\text { lugar. }\end{array}$ & $\begin{array}{c}(\mathrm{CCL}) \\
(\mathrm{CSC}) \\
(\mathrm{CMCT}) \\
(\mathrm{CD}) \\
(\mathrm{CAA}) \\
(\mathrm{SIEP}) \\
(\mathrm{CEC})\end{array}$ \\
\hline $\begin{array}{c}\text { Quinto } \\
\text { PID }\end{array}$ & $\begin{array}{l}\text { Necrópolis de } \\
\text { Laurita }\end{array}$ & $\begin{array}{l}\text { Cronología, coordenadas, altitud, orientación, } \\
\text { características. } \\
\text { El rito de la incineración que posteriormente (S. V a } \\
\text { C) será sustituido por el de la inhumación, se detecta } \\
\text { en las veinte sepulturas de pozo allí existentes. } \\
\text { Cuyas cenizas se depositaban en urnas de alabastro. } \\
\text { El expolio que sufrió fue muy grande. ¿Es admisible } \\
\text { que unos pocos se apropien del patrimonio de todos? } \\
\text { Justifica tu respuesta } \\
\text { La necrópolis está en una propiedad privada. ¿Es } \\
\text { admisible que un patrimonio tan importante para la } \\
\text { ciudad no pueda ser visitado por la población? } \\
\text { Describe e investiga, incluso preguntando a } \\
\text { tus familiares y amigos, su estado de acceso/ } \\
\text { conservación/protección. }\end{array}$ & $\begin{array}{c}\text { (CCL) } \\
(\mathrm{CSC}) \\
(\mathrm{CMCT}) \\
(\mathrm{CD}) \\
(\mathrm{CAA}) \\
(\mathrm{SIEP}) \\
(\mathrm{CEC})\end{array}$ \\
\hline $\begin{array}{l}\text { Sexto } \\
\text { PID }\end{array}$ & $\begin{array}{l}\text { Necrópolis de } \\
\text { Puente de Noy }\end{array}$ & $\begin{array}{l}\text { Cronología, coordenadas, altitud, orientación, } \\
\text { características. } \\
\text { Investiga qué explicaciones relacionadas con los } \\
\text { materiales geológicos de esta zona explican que aquí } \\
\text { se construyese la necrópolis. } \\
\text { El rito incluirá ya la inhumación y se sustituye el } \\
\text { alabastro por la cerámica en la que los fenicios } \\
\text { destacaron como alfareros. } \\
\text { ¿Qué ventajas tiene utilizar la cerámica? } \\
\text { Es la que contiene restos fenicios más recientes: } \\
\text { amuletos con el ojo Horus y figurillas con } \\
\text { divinidades egipcias. Investiga las creencias de los } \\
\text { fenicios. } \\
\text { Describe e investiga, incluso preguntando a } \\
\text { tus familiares y amigos, su estado de acceso/ } \\
\text { conservación/protección. }\end{array}$ & $\begin{array}{c}\text { (CCL) } \\
(\mathrm{CSC}) \\
(\mathrm{CMCT}) \\
(\mathrm{CD}) \\
(\mathrm{CAA}) \\
(\mathrm{SIEP}) \\
(\mathrm{CEC})\end{array}$ \\
\hline
\end{tabular}

TABLA $\mathrm{N}^{\mathrm{O}} 1$. Actividades a realizar, contenidos a reflexionar y competencias clave a trabajar en los PID. 


\subsection{Evaluación del proceso de aprendizaje}

Para evaluar el proceso de aprendizaje del alumnado se ha tenido en cuenta el cuaderno de campo y el producto final (carta reivindicativa). El cuaderno constituye un instrumento de evaluación en sí mismo que permitirá comprobar el grado de consecución de las competencias clave. Por otro lado, para evaluar el producto final se utilizará una rúbrica para medir el nivel de desarrollo de las competencias sociales y cívicas de manera más específica, tal como muestra la Tabla 2.

\begin{tabular}{|c|c|c|c|c|}
\hline CATEGORÍA & Excelente (5) & $\begin{array}{c}\text { Muy bueno } \\
(3-4)\end{array}$ & Bueno (2) & Regular (1) \\
\hline \multicolumn{5}{|c|}{ FORMATO DE LA CARTA } \\
\hline TÍTULO & $\begin{array}{l}\text { Es muy creativo } \\
\text { y sugerente, y } \\
\text { resume muy bien } \\
\text { la idea principal } \\
\text { del tema }\end{array}$ & $\begin{array}{l}\text { Es creativo y } \\
\text { sugerente, y } \\
\text { resume bien la } \\
\text { idea principal } \\
\text { del tema }\end{array}$ & $\begin{array}{l}\text { Resume la idea } \\
\text { principal del } \\
\text { tema }\end{array}$ & $\begin{array}{l}\text { No resume la idea } \\
\text { principal del tema }\end{array}$ \\
\hline $\begin{array}{c}\text { REDACCIÓN Y } \\
\text { CONSTRUCCIÓN } \\
\text { DE PÁRRAFOS }\end{array}$ & $\begin{array}{l}\text { No hay errores de } \\
\text { gramática y todos } \\
\text { los párrafos son } \\
\text { coherentes }\end{array}$ & $\begin{array}{l}\text { Hay algunos } \\
\text { errores de } \\
\text { gramática y la } \\
\text { mayor parte } \\
\text { de los párrafos } \\
\text { son coherentes }\end{array}$ & $\begin{array}{l}\text { Hay errores } \\
\text { de gramática } \\
\text { y los párrafos } \\
\text { incluyen } \\
\text { información } \\
\text { relacionada } \\
\text { pero no se } \\
\text { hallan bien } \\
\text { organizados }\end{array}$ & $\begin{array}{l}\text { Existen muchos } \\
\text { errores de } \\
\text { gramática y la } \\
\text { estructura de los } \\
\text { párrafos no es clara }\end{array}$ \\
\hline ORGANIZACIÓN & $\begin{array}{l}\text { La información } \\
\text { está muy bien } \\
\text { organizada, } \\
\text { existiendo un } \\
\text { orden lógico en el } \\
\text { discurso. El texto } \\
\text { es claramente } \\
\text { comprensible }\end{array}$ & $\begin{array}{l}\text { La información } \\
\text { está bien } \\
\text { organizada, } \\
\text { existiendo un } \\
\text { orden lógico } \\
\text { en el discurso. } \\
\text { El texto es } \\
\text { comprensible }\end{array}$ & $\begin{array}{l}\text { La información } \\
\text { no siempre está } \\
\text { organizada, por } \\
\text { lo que falla el } \\
\text { orden lógico } \\
\text { del discurso. } \\
\text { Pero el texto es } \\
\text { comprensible }\end{array}$ & $\begin{array}{c}\text { La información } \\
\text { no está organizada } \\
\text { y el texto no } \\
\text { es fácilmente } \\
\text { comprensible }\end{array}$ \\
\hline \multicolumn{5}{|c|}{ CONTENIDO DE LA CARTA Y LOGRO DE LAS CSC } \\
\hline $\begin{array}{l}\text { REFLEXIÓN } \\
\text { CRÍTICA }\end{array}$ & $\begin{array}{l}\text { Argumenta la } \\
\text { necesidad de } \\
\text { proteger/valorar } \\
\text { el patrimonio } \\
\text { arqueológico }\end{array}$ & $\begin{array}{l}\text { Hay algunos } \\
\text { argumentos } \\
\text { sobre la } \\
\text { necesidad } \\
\text { de proteger/ } \\
\text { valorar el } \\
\text { patrimonio }\end{array}$ & $\begin{array}{l}\text { Los argumentos } \\
\text { no están bien } \\
\text { fundamentados }\end{array}$ & $\begin{array}{c}\text { No hay argumentos } \\
\text { que justifiquen } \\
\text { la necesidad de } \\
\text { proteger/valorar el } \\
\text { patrimonio }\end{array}$ \\
\hline
\end{tabular}




\begin{tabular}{|c|c|c|c|c|}
\hline $\begin{array}{c}\text { PROPUESTA DE } \\
\text { MEJORA }\end{array}$ & $\begin{array}{c}\text { Se exponen } \\
\text { propuestas reales } \\
\text { para conservar el } \\
\text { patrimonio }\end{array}$ & $\begin{array}{c}\text { Se exponen } \\
\text { algunas } \\
\text { propuestas } \\
\text { reales para } \\
\text { conservarlo }\end{array}$ & $\begin{array}{c}\text { Las propuestas } \\
\text { no están claras }\end{array}$ & $\begin{array}{c}\text { No hay propuestas } \\
\text { reales para } \\
\text { conservar el } \\
\text { patrimonio }\end{array}$ \\
\hline $\begin{array}{c}\text { BENEFICIO A LA } \\
\text { COMUNIDAD }\end{array}$ & $\begin{array}{c}\text { Se incluyen los } \\
\text { beneficios de la } \\
\text { puesta en valor }\end{array}$ & $\begin{array}{c}\text { Se incluyen } \\
\text { algunos } \\
\text { beneficios de la } \\
\text { puesta en valor }\end{array}$ & $\begin{array}{c}\text { Hay pocos } \\
\text { beneficios de la } \\
\text { puesta en valor }\end{array}$ & $\begin{array}{c}\text { No existen } \\
\text { beneficios de la } \\
\text { puesta en valor }\end{array}$ \\
\hline FOTOGRAFÍAS & $\begin{array}{c}\text { Son nítidas } \\
\text { y muestran } \\
\text { el deterioro } \\
\text { de los restos } \\
\text { arqueológicos }\end{array}$ & $\begin{array}{c}\text { Muestran } \\
\text { el deterioro } \\
\text { pero algunas } \\
\text { fotografías no } \\
\text { se observan } \\
\text { con claridad }\end{array}$ & $\begin{array}{c}\text { No muestran } \\
\text { el deterioro } \\
\text { de los restos } \\
\text { arqueológicos }\end{array}$ & $\begin{array}{c}\text { No incluye } \\
\text { fotografías }\end{array}$ \\
& \multicolumn{2}{|c}{} & \\
\hline
\end{tabular}

TABLA N ${ }^{\circ}$ 2. Rúbrica para la evaluación del producto final (carta grupal reivindicativa)

\section{CONCLUSIONES}

En el presente trabajo se ha elaborado una propuesta de itinerario didáctico dirigido al alumnado de $1^{\circ}$ de ESO y que pone el énfasis en el desarrollo de las competencias clave y de manera más específica en el desarrollo de las competencias sociales y cívicas (CSC). Desde hace décadas, la aplicación de itinerarios didácticos en enseñanzas medias y, en concreto, en la materia de Geografía e Historia, ha reportado grandes beneficios en los discentes y en la mejora del proceso de enseñanza-aprendizaje. Se parte del convencimiento de que los jóvenes de este nivel educativo pueden adquirir y reforzar mejor sus conocimientos básicos (humanísticos, científicos y tecnológicos), sus hábitos de trabajo/estudio e iniciarse en el ejercicio y desarrollo de sus derechos y obligaciones ciudadanas, a través de este recurso pedagógico, cuando se centra en su espacio vivido, sentido y considerado como propio.

El itinerario propuesto se centra en el patrimonio arqueológico de origen fenicio existente en el municipio de Almuñécar. A lo largo de los seis PID seleccionados se constata la gran importancia de los restos y el enorme potencial didáctico que aportan. Sin embargo, se encuentran infrautilizados y precisan de medidas urgentes para su puesta en valor y conservación. A través de tres fases diferenciadas (antes, durante, post) y con la ayuda de diferentes recursos didácticos, un cuaderno de campo y una propuesta de actividades exclusiva para cada PID, se desarrolla el conjunto de competencias clave realzando el papel de las competencias sociales y cívicas como objetivo principal de este trabajo. Estas fases generarán como resultado un producto final o carta reivindicativa 
elaborada por el alumnado y dirigida a las autoridades pertinentes, a fin de que pongan los medios necesarios para su puesta en valor. De esta manera el alumnado de $1^{\circ}$ de ESO se inicia en el ejercicio de sus derechos y obligaciones cívicas, tratando de mejorar, con el concurso de toda la comunidad educativa, la realidad de la ciudad en la que viven (espacio vivido), evitando el deterioro del patrimonio más emblemático del municipio de Almuñécar, propiciando su puesta en valor y, en definitiva su desarrollo sostenible (ODS, 4, 8, 9, 11,16).

En definitiva, el itinerario didáctico constituye una herramienta metodológica fundamental para el desarrollo de las competencias clave en el alumnado de enseñanzas medias, tal como se ha mostrado en este trabajo. A pesar de no haber sido llevado a la práctica en la realidad se pretende aplicarlo en el próximo curso académico para obtener resultados más objetivos y corregir los posibles déficits que puedan derivarse de su aplicación.

\section{BIBLIOGRAFÍA}

Adroher, A. y Cobos, A., 2007. De marineros a ciudadanos. El mundo fenicio en la costa granadina entre los siglos IX y I a.C. Patrimonio Arqueológico de la Costa de Granada. De la prehistoria a la Edad Moderna. España: Ed. Ayuntamiento de Gualchos-Castell de Ferro y Diputación de Granada.

Alcántara, J. A., y Medina, S., 2019. "El uso de los itinerarios didácticos (SIG) en la educación ambiental". Enseñanza de las ciencias: revista de investigación y experiencias didácticas, 37(2), pp. 173-188.

Arribas Palau, A., 2009. "Nuevos hallazgos fenicios en la costa andaluza mediterránea". Zephyrus, 18, pp. 11.

Bravo Jiménez, S., 2000. "Evolución y poblamiento fenicio en la costa mediterránea andaluza. Espacio, Tiempo y Forma". Historia Antigua, 13, pp. 13-44.

Crespo Castellanos, J. M., 2012. "Un itinerario didáctico para la interpretación de los elementos físicos de los paisajes de la Sierra de Guadarrama”. Revista Didáctica Geográfica, 13, pp. 15-34.

Decreto 111/2016, de 14 de junio, por el que se establece la ordenación y el currículo de la educación secundaria obligatoria en la comunidad autónoma de Andalucía (BOJA 28-06-2016).

García, J., Sánchez, I., Adroher, A., Dorado, A., Larios, R., Maroto, R.,...Urquieta, E., 2018. "El yacimiento arqueológico de Monte Velilla (Almuñécar, Granada)" en Universidad de Granada, ed. Yacimientos arqueológicos y artefactos. Las colecciones del departamento de prehistoria y arqueología (I), pp. 91-95. 
El desarrollo de las competencias sociales y cívicas en Ciencias Sociales: itinerario didáctico...

García Ruiz,A., 1993. Los trabajos de campo: Visitas de Estudios Itinerarios Didácticos. Sevilla: Didáctica de las Ciencias Sociales en la Educación Primaria, Algaida.

García Ruiz, A., 1994. Los Itinerarios Didácticos, una de las claves para la Enseñanza y Comprensión de la Geografía. Barcelona: Íber, 1, GRAÓ.

Gómez Ortiz, A., 1986. "Los itinerarios pedagógicos como recurso didáctico en la enseñanza de Geografía en EGB”. Revista Didáctica Geográfica, 14, pp. 109-116.

Gómez Gonçalves, A., Corrochano Fernández, D. y Parra Nieto, G., 2017. "Itinerarios didáctico-naturales en Educación Primaria: el noroeste de Zamora". Revista Didáctica Geográfica, 18, pp. 111-131.

Insa, Y., 2002. "Itinerarios urbanos, recursos y materiales didácticos para explicar la ciudad". Íber, Didáctica de las ciencias sociales: Geografía e Historia, 32, pp. 89-95.

Liceras, Á. 2000. Tratamiento de las dificultades de aprendizaje en Ciencias Sociales. Grupo Editorial Universitario Granada.

Liceras, Á., 2018. "Los itinerarios didácticos en la enseñanza de la geografía. Reflexiones y propuestas acerca de su eficacia en educación”. Revista UNES. Universidad, Escuela y Sociedad, (5), pp. 66-81.

Liceras, Á. y Romero, G. 2016. Didáctica de las Ciencias Sociales. Fundamentos, contextos y propuestas. Madrid: Pirámide.

Maroto Martos, J. C. y Najarro Martín, U., 2018. Un recorrido por los restos fenicios de Almuñécar (Granada, España), medio para mejorar su turismo cultural. Actas del I Congreso Internacional Turismo Transversal y Paisaje TOURISCAPE, Torremolinos, Málaga, España, pp. 142-154.

Mederos Martín,A. y Ruíz Cabro, L.A., 2002. "La fundación de Sexi-Laurita (Almuñécar, Granada) y los orígenes de la penetración fenicia en la vega de Granada, homenaje a Manuel Pellicer". Spal, 10, pp. 41-67.

Mínguez García, Mª ., 2010. "El paisaje como objeto de estudio de la Geografía. Un itinerario didáctico en el marco de la semana de la ciencia de la Comunidad de Madrid". Revista Didáctica Geográfica, 11, pp. 37-62.

Molina Fajardo, F. Ruíz Fernández, A. y Huertas Jiménez, C., 1982. La necrópolis fenicio-púnica de Puente de Noy I. Granada: Almuñécar en la antigüedad.

Molina Fajardo, F. y Jiménez Contreras, S., 1983. "La factoría de salazones El Majuelo". Almuñécar, Arqueología e Historia I, pp. 279-190.

Molina Fajardo, F., Huertas Jiménez, C. y López Castro, J. L., 1984. "Hallazgos púnicos en El Majuelo". Almuñécar, Arqueología e Historia II, Granada, pp. 275-289. 
Molina Fajardo, F. y Huertas Jiménez, C., 1985. La necrópolis fenicio-púnica de Puente de Noy II. Granada: Almuñécar en la antigüedad.

Molina Fajardo, F., 1986. "Almuñécar a la luz de los nuevos hallazgos fenicios, los fenicios en la Península Ibérica”. Ausa, 1, pp. 193-216.

Olave Farías, D., 2005. "El itinerario didáctico: una propuesta metodológica para el análisis geo-histórico local”. Revista Geoenseñanza, 10, pp. 197-208.

Orden ECD/65/2015, de 21 de enero, por la que se describen las relaciones entre las competencias, los contenidos y los criterios de evaluación de la educación primaria, la educación secundaria obligatoria y el bachillerato. Boletín Oficial del Estado. Madrid, 29 de enero de 2015, nº 25, pp. 6986-7003.

Pastor Muñoz, M., 1983. "Fuentes antiguas sobre Almuñécar (Sexi Firmum Iulium)". Almuñécar, Arqueología e Historia, Granada, pp. 205-235.

Pastor Muñoz, M., 2000. "Fuentes antiguas sobre Almuñécar”. Almuñécar, Arqueología e Historia, Granada, pp. 13-29.

Pellicer, M., 1963. Excavaciones en la necrópolis púnica Laurita del Cerro de San Cristóbal (Almuñécar, Granada). Madrid: Excavaciones Arqueológicas en España 17.

Pellicer, M., 1985. “Sexi fenicia y púnica”. Aula Orientalis III, 12, pp. 85-107.

Pellicer, M., 2007. La necrópolis Laurita (Almuñécar, Granada) en el contexto de la colonización fenicia. Barcelona: Cuadernos de Arqueología Mediterránea 15.

Pontuschka, N., Paganelli, T. y Cacete, N., 2007. Para ensinar e aprender Geografia. Sao Paulo: Cortez editor.

Real Decreto 1105/2014, de 26 de diciembre, por el que se establece el currículo básico de la Educación Secundaria Obligatoria y del Bachillerato. Boletín Oficial del Estado. Madrid, 3 enero de 2015, n 3, pp. 169-546.

Sánchez López, E., 2013. "El puerto de Sexi Firmum Iulium. Evidencias de una estructura portuaria en las excavaciones realizadas en 1972 en el majuelo (Almuñécar, Granada)". Revista Zephyrus, 72, pp. 139-151.

Sancho Comíns, J., 1996. "El mapa como recurso didáctico en la enseñanza y aprendizaje de la Geografía”. Revista Didáctica Geográfica, 1, pp. 15-20.

Sierra Santos, G., 2009. El mar como frontera. Castillos y fortalezas de Almuñécar y La Herradura. España: Granada. Ediciones Garum.

Sobrado, L., 2000. Educación psicopedagógica y orientación educativa. Ed. Stel. Barcelona.

Sotomayor, M., 1971. "Nueva factoría de salazones de pescado en Almuñécar (Granada)". Noticiario Arqueológico Hispánico, 15, pp. 148-178. 